\title{
Chain stopper engineering for hydrogen bonded supramolecular polymers
}

\author{
Thomas Pinault $^{1,2}$, Bruno Andrioletti ${ }^{3}$ and Laurent Bouteiller ${ }^{*} 1,2$
}

\section{Full Research Paper}

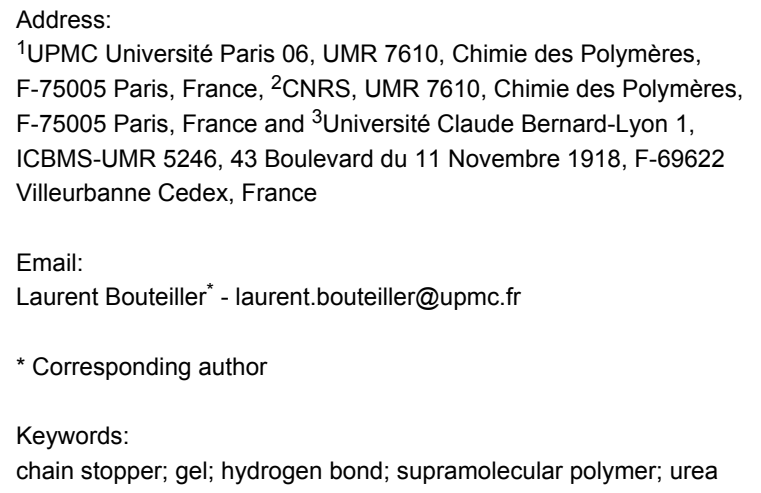

Keywords:

chain stopper; gel; hydrogen bond; supramolecular polymer; urea

\begin{abstract}
Supramolecular polymers are linear chains of low molar mass monomers held together by reversible and directional non-covalent interactions, which can form gels or highly viscous solutions if the self-assembled chains are sufficiently long and rigid. The viscosity of these solutions can be controlled by adding monofunctional compounds, which interact with the chain extremities: chain stoppers. We have synthesized new substituted ureas and thioureas and tested them as chain stoppers for a bis-urea based supramolecular polymer. In particular, the bis-thiourea analogue of the bis-urea monomer is shown not to form a supramolecular polymer, but a good chain stopper, because it is a strong hydrogen bond donor and a weak acceptor. Moreover, all substituted ureas tested reduce the viscosity of the supramolecular polymer solutions, but the best chain stopper is obtained when two hydrogen bond acceptors are placed in the same relative position as for the monomer and when no hydrogen bond donor is present.
\end{abstract}

\section{Introduction}

Supramolecular polymers are linear chains of low molar mass monomers held together by reversible and highly directional non-covalent interactions [1-3]. Because of their macromolecular architecture, they can display polymer-like rheological properties, and they can, in particular, form gels if the selfassembled chains are sufficiently long and rigid [4-9]. Compared to the well-known organogelators formed by the entanglement of usually crystalline fibers [10-13], supramolecular polymers display some specific features. In particular, hydrogen-bonded supramolecular polymers are often dynamic at room temperature, which means that they do not need to be heated and then cooled to form a gel. Moreover, the gels formed are usually visco-elastic, meaning that they show an elastic response only at high frequencies.

The chain length of a supramolecular polymer depends on the strength of the association between the monomers, which is highly dependent on their concentration, the temperature, the solvent, i.e., environmental factors, but also on the presence of additives. Chain-stoppers are monofunctional monomers able to 
interact with monomers and therefore able to break polymer chains. They can be introduced in order to reduce the length of the supramolecular polymer (and thus reduce the viscosity of the solution) [14-16], but also in order to block the concentration dependence of the supramolecular polymers [17-19]. Chain stoppers can also be exploited to decorate the chain-ends with particular functional groups or labels [20,21]. The effectiveness of these schemes depends directly on the design of the chainstopper: the interaction between chain-stopper and monomer should ideally be as strong as the interaction between monomers. It is therefore of interest to identify chain stoppers with an improved affinity toward a given supramolecular polymer. In this article, we investigate the efficiency of several new chain stoppers for a well-known bis-urea-based supramolecular polymer EHUT (Figure 1). This supramolecular polymer is particularly interesting, because it has been previously shown to self-assemble cooperatively into two competitive high molecular weight structures [22-24].

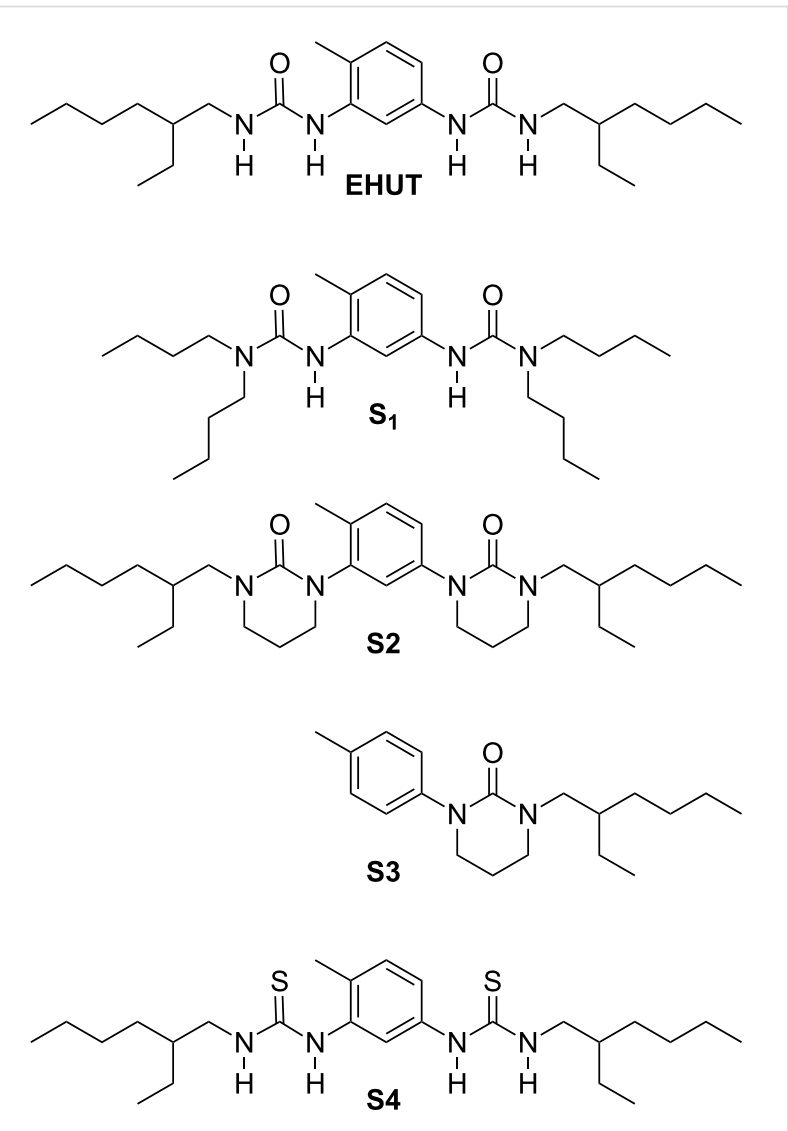

Figure 1: Structures of monomer EHUT and chain stoppers.

\section{Results and Discussion Design and synthesis}

The bis-urea based monomer EHUT has been shown to selfassemble in non-polar solvents, into two supramolecular poly- meric structures, the tube or the filament forms, which are in dynamic exchange $[23,24]$. The respective stability of each form depends on the solvent, the temperature and the concentration. The filament form contains a single molecule in its cross section [25-27], and is the most stable structure at concentrations above $10^{-3} \mathrm{~mol} / \mathrm{L}$ and at room temperature, in solvents such as chloroform [22], carbon tetrachloride [28] and 1,3,5trimethylbenzene [29]. The tube form contains three molecules in its cross section [6,30,31], and is the most stable structure at concentrations above $10^{-5} \mathrm{~mol} / \mathrm{L}$ and at room temperature, in solvents such as toluene [32] and dodecane [5].

Chain stopper S1, with two NH groups replaced by $N$-butyl groups, was previously shown to be a good chain stopper for EHUT in carbon tetrachloride [17], i.e., a good chain stopper of the filament form. However, at high concentrations, the two remaining $\mathrm{NH}$ groups were shown to form hydrogen bonds [17], and therefore $\mathbf{S 1}$ can also behave to some extent as a co-monomer of EHUT: a small proportion of S1 molecules may be incorporated in the filament structure rather than at its extremities. Simple alkylation of the 2 remaining NH groups does not yield an efficient chain stopper [17]. This surprising result was tentatively attributed to the conformation of the tetrasubstituted urea group, which may be ill-adapted to form hydrogen bonds to the urea groups of EHUT (Figure 2).

Hence, we introduced cyclic urea groups in the structure of chain stopper S2, by the alkylation of EHUT with 1,3-dibromopropane [33]. The rigidity of the cyclic ureas forbids any conformational rearrangement and should make it possible to probe whether the presence of $\mathrm{NH}$ functions in $\mathbf{S 1}$ significantly affects the chain stopper efficiency. In order to see if both urea carbonyls in $\mathbf{S 2}$ interact cooperatively with EHUT assemblies ,the mono-urea stopper $\mathbf{S 3}$ was also prepared. Finally, chain stopper $\mathbf{S 2}$ can only interact with bis-urea assemblies as a hydrogen bond acceptor through its carbonyl groups. It is therefore of interest to try and design a potentially complementary chain stopper, which would interact with bis-urea assemblies as a hydrogen bond donor. For this purpose, we synthesized the bis-thiourea $\mathbf{S 4}$, from the corresponding bis-thioisocyanate, because thioureas are known to be strong hydrogen bond donors and weak hydrogen bond acceptors $[34,35]$.

Before evaluating the chain stopper efficiency of these compounds, i.e., their interaction with EHUT, their self-association was probed.

\section{Self-association of bis-thiourea}

Chain stoppers $\mathbf{S 2}$ and $\mathbf{S 3}$ cannot self-associate because they contain only hydrogen bond acceptors, however this is not the case for $\mathbf{S 4}$, and it is of interest to determine the conditions 
a)<smiles>[R]N(C(=O)N(CCCC)CCCC)c1ccccc1</smiles><smiles>[R]N(C(=O)N(CCCC)CCCC)c1ccc(C)c(N([R])C(=O)N(CCCC)CCCC)c1</smiles>

b)<smiles>[R]N(C(=O)N(CCCC)CCCC)c1ccccc1</smiles>

b)<smiles>[R]N(C(=O)N(CCCC)CCCC)c1ccc(C)c(N([R])C(=O)N(CCCC)CCCC)c1</smiles>

Figure 2: Substituted urea conformation. If $\mathrm{R}$ is alkyl, the most stable conformation is $\mathrm{b}$ ); if $\mathrm{R}=\mathrm{H}$, the most stable conformation is a) [37].

under which $\mathbf{S 4}$ can be considered not to associate with itself. Figure 3a shows the FTIR spectra of $\mathbf{S 4}$ at several concentrations in chloroform. At concentrations below $53 \mathrm{mM}$, a single band is visible in the region corresponding to the $\mathrm{N}-\mathrm{H}$ stretching vibration. This band $\left(3405 \mathrm{~cm}^{-1}\right)$ can be attributed to free NH groups. Only at a high concentration $(0.5 \mathrm{~mol} / \mathrm{L})$ does a band characteristic for hydrogen bonded $\mathrm{NH}$ groups appear $\left(3250 \mathrm{~cm}^{-1}\right)$. The very weak hydrogen bonding propensity of bis-thiourea S4 is particularly obvious when compared to bisurea EHUT (Figure 3b): at the same concentration ( $9 \mathrm{mM})$, the bis-urea is nearly fully associated, whereas the bis-thiourea is virtually not associated. The respective behaviour of the bisurea and the bis-thiourea was also probed by Small Angle Neutron Scattering (SANS) in toluene. Figure 4 shows the previously established $\mathrm{q}^{-1}$ dependence of EHUT, which is characteristic for long and rigid fibrillar scatterers [23]. In contrast, the low intensity and flat profil for $\mathbf{S 4}$ at small angles is characteristic for small globular scatterers. A fit was performed with the form factor of a sphere, and yields a diameter of $22 \AA$, which is comparable to the largest dimension of the fully extended molecule ( $25 \AA$ ). In conclusion, bis-thiourea S4 does not self-assemble significantly at concentrations below $12 \mathrm{mM}$ in toluene or $53 \mathrm{mM}$ in chloroform.

\section{Chain stopper effect on the EHUT filament structure}

Viscosimetry is certainly the most sensitive technique to probe the efficiency of a chain stopper on supramolecular polymers. Therefore, we measured the viscosity of solutions of EHUT at a fixed concentration $(20 \mathrm{mM})$ with increasing amounts of chain stopper. For this, 1,3,5-trimethylbenzene was chosen as the solvent because it is known to favor the formation of EHUT filaments at room temperature [29]. Figure 5 shows that all four compounds strongly reduce the relative viscosity of EHUT,

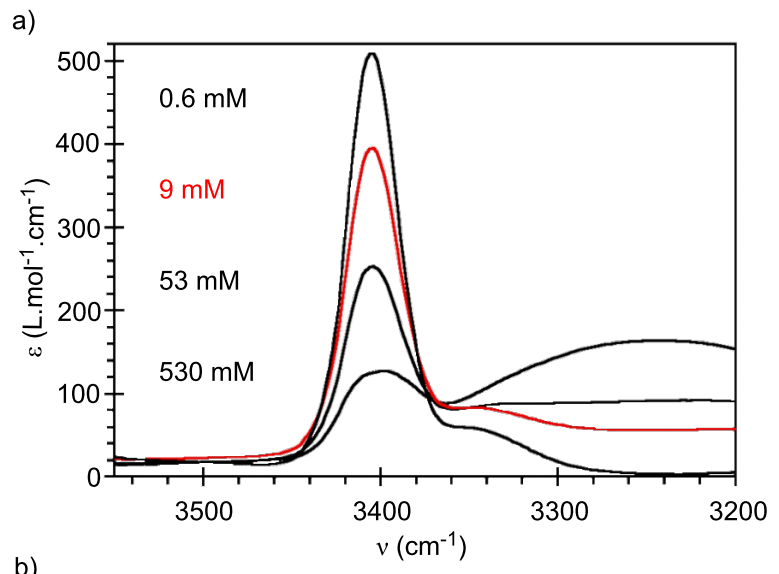

b)

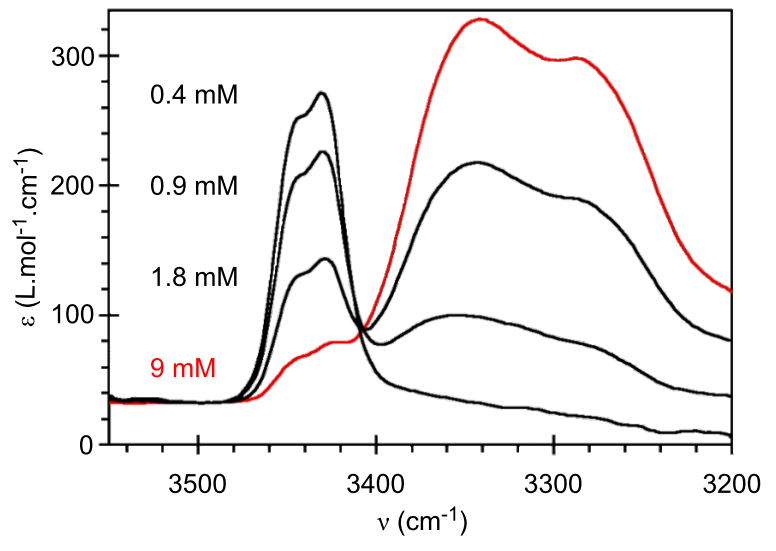

Figure 3: FTIR spectra, at $20^{\circ} \mathrm{C}$, for $\mathrm{CDCl}_{3}$ solutions of $\mathbf{S 4}$ (a) or EHUT (b), at several concentrations.

which decreases from a value of 7.6 in the absence of stopper to a value close to 1 (i.e. the solution has approximately the same viscosity as the solvent) for a molar fraction ratio of stopper to monomer of 0.1 . However, there are some significant differ- 


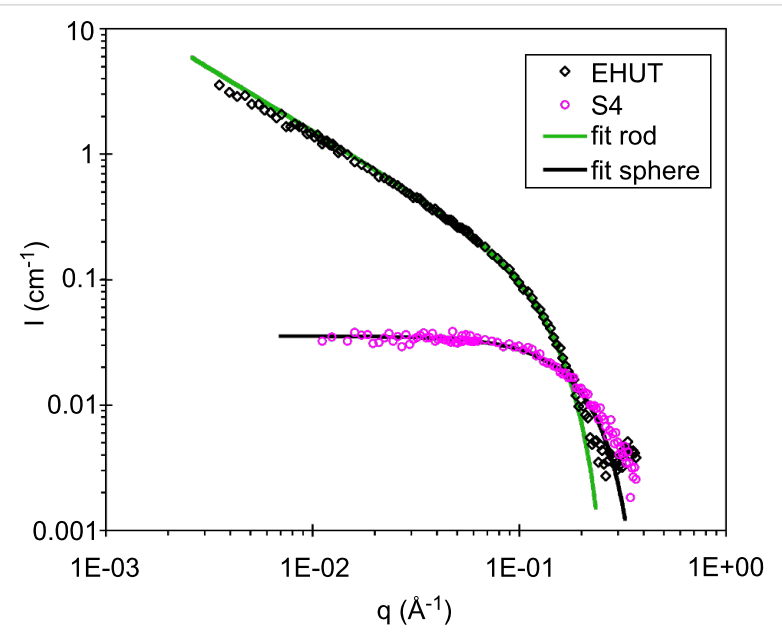

Figure 4: SANS intensity versus scattering vector for $12 \mathrm{mM}$ solutions of EHUT or $\mathbf{S} 4$ in $d_{8}$-toluene, at $22{ }^{\circ} \mathrm{C}$. The plain curves are fits according to a model for infinitely long rigid rods of diameter $26 \AA$ (green), or for spheres of diameter $22 \AA$ (black).

ences between the stoppers: their efficiency increases in the order $\mathbf{S 1}<\mathbf{S 3} \approx \mathbf{S} 4<\mathbf{S 2}$. Several conclusions can be derived from this result. First, the lower viscosity of solutions containing $\mathbf{S 2}$ than those containing $\mathbf{S 1}$ means that the remaining two $\mathbf{N H}$ groups of $\mathbf{S} \mathbf{1}$ do participate in hydrogen bonding and reduce the efficiency of the stopper. Secondly, the lower viscosity of solutions containing $\mathbf{S 2}$ than those containing $\mathbf{S 3}$ indicates that both carbonyls are probably involved in the association between $\mathbf{S 2}$ and an EHUT filament. Finally, bisthiourea $\mathbf{S 4}$ is a reasonably good chain stopper. The fact that it is not as good as $\mathbf{S 2}$ is perhaps due to some marginal hydrogen bonding involving the thiocarbonyl groups.

\section{Chain stopper effect on the EHUT tube struc- ture}

For the above, toluene was chosen as the solvent, because it is known to favor the formation of EHUT tubes at room temperature [32] and has a similar polarity as 1,3,5-trimethylbenzene. Figure 6 shows that all four compounds also reduce the relative viscosity of EHUT in toluene, but the situation is more complex than in trimethylbenzene. If we consider first the part of the curves with a stopper to monomer fraction lower than 0.05 , the efficiency of the chain stoppers increases in the order $\mathbf{S 3}<\mathbf{S 1} \approx \mathbf{S 4}<\mathbf{S 2}$. Therefore, the same conclusions for the interactions with the EHUT tubes can be derived as for the interactions with the EHUT filaments: i) the lower viscosity of solutions containing $\mathbf{S} 2$ than those containing $\mathbf{S 1}$ means that the remaining two $\mathbf{N H}$ groups of $\mathbf{S} \mathbf{1}$ participate in hydrogen bonding and reduce the efficiency of the stopper; ii) the lower viscosity of solutions containing $\mathbf{S 2}$ than those containing $\mathbf{S 3}$ indicates that both carbonyl groups are involved in the association between $\mathbf{S 2}$ and an EHUT tube; and iii) bis-thiourea $\mathbf{S 4}$ is

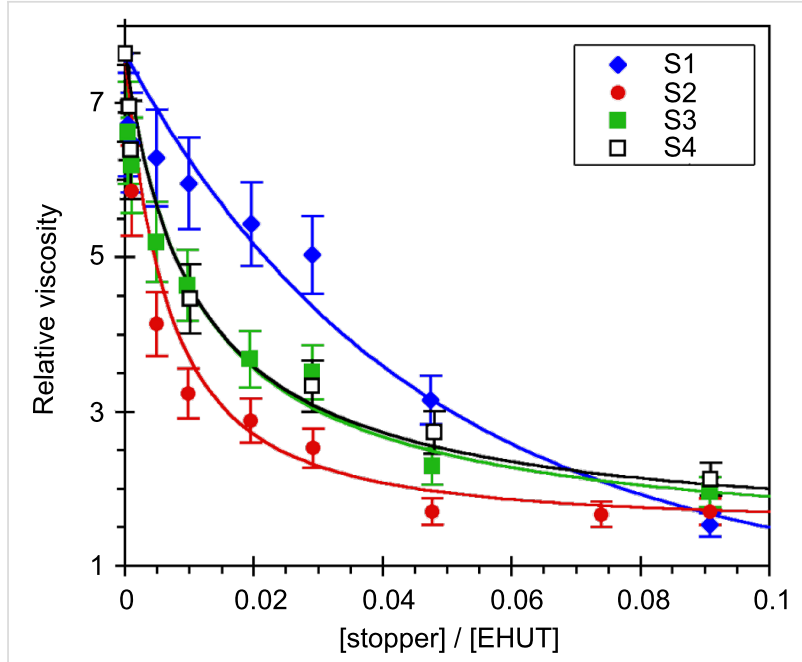

Figure 5: Relative viscosity for solutions of EHUT (20 mM) in 1,3,5trimethylbenzene at $25^{\circ} \mathrm{C}$, with increasing molar fraction of chain stoppers. The lines are a guide for the eye only.

a reasonably good chain stopper, but not as good as $\mathbf{S 2}$ probably due to some marginal hydrogen bonding involving the thiocarbonyls. If we consider now the part of the curves with a stopper to monomer fraction larger than 0.05 , it is surprising to see that instead of the value decreasing to 1 , the relative viscosity reaches a plateau at a value of 5 and 4 in the cases of S1 and S2, respectively. To our knowledge, such a saturating effect is unprecedented, and may indicate that an additional mechanism is involved in the interaction between the bis-urea tubes and $\mathbf{S 1}$ or $\mathbf{S 2}$. For example, we can hypothesize that at sufficiently high concentrations, $\mathbf{S} 1$ or $\mathbf{S 2}$ do not only interact with the extremities of the tubes, but also anywhere along them,

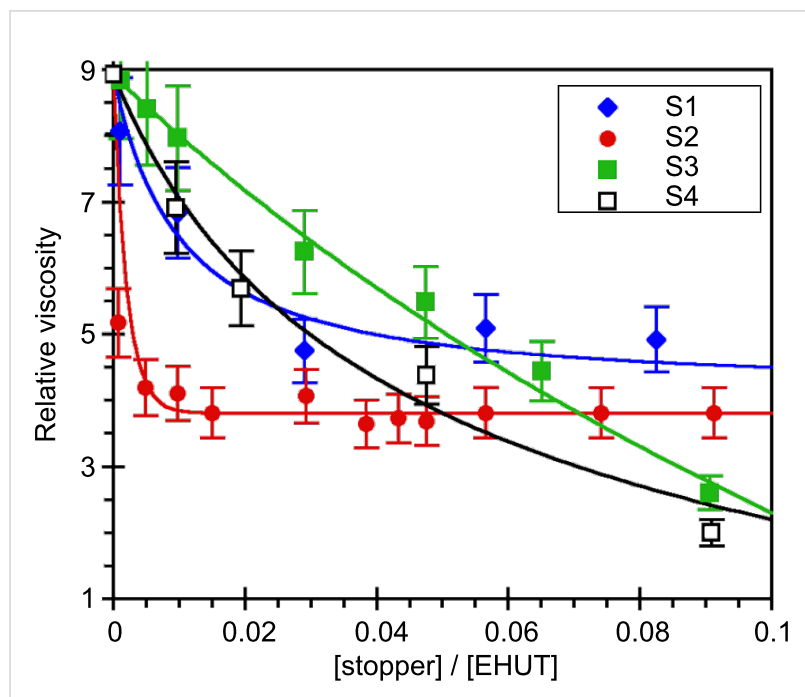

Figure 6: Relative viscosity for solutions of EHUT $(1.1 \mathrm{mM})$ in toluene at $25^{\circ} \mathrm{C}$, with increasing molar fraction of chain stoppers. The lines are a guide for the eye only. 
without breaking them. However, additional characterizations will be required to test this interpretation [36].

\section{Conclusion}

We have synthesized new substituted ureas and thioureas and tested them as chain stoppers for a bis-urea based supramolecular polymer. Depending on the solvent used, the bis-urea either forms filaments with a single monomer in the crosssection or tubes with three monomers in the cross-section. For both supramolecular architectures, similar conclusions can be derived: while all compounds tested reduce the viscosity of the supramolecular polymer solutions, the best chain stopper is obtained when two hydrogen bond acceptors are placed in the same relative position as for the monomer, and when no hydrogen bond donor is present.

Moreover, we have shown that a bis-thiourea with the same structure as the bis-urea monomer does not to form a supramolecular polymer, but acts as a good chain stopper, because it is a strong hydrogen bond donor and a weak acceptor.

\section{Experimental Synthesis}

The synthesis of EHUT [32] and chain stopper S1 [17] have previously been reported.

Chain stopper S2. NaH (9 g) was placed in a three necked round bottomed flask and washed with pentane $(25 \mathrm{~mL})$ under a nitrogen atmosphere. An EHUT solution (4.32 g, $10 \mathrm{mmol}$ ) in dry THF $(400 \mathrm{~mL})$ was added and the mixture stirred for $1 \mathrm{~h}$. 1,3-Dibromopropane $(20.5 \mathrm{~mL}, 200 \mathrm{mmol})$ in dry THF (100 $\mathrm{mL}$ ) was then added, and the solution heated under reflux for 24 h. After cooling, ice was slowly added and the solvent evaporated. Chloroform $(200 \mathrm{~mL})$ was added and the organic phase washed successively with brine $(300 \mathrm{~mL})$ and water $(2 \times 300$ $\mathrm{mL}$ ), dried over magnesium sulfate and concentrated. Silica gel column chromatography (ethyl acetate) followed by recrystallization from pentane afforded $1.9 \mathrm{~g}$ of a white solid $(37 \%) .{ }^{1} \mathrm{H}$ NMR (200 MHz, DMSO- $\left.d_{6}\right): \delta(\mathrm{ppm})=7.2(\mathrm{~d}, J=1.5 \mathrm{~Hz}, 1 \mathrm{H}$, $\operatorname{Ar}-H), 7.12(\mathrm{~d}, J=8.1 \mathrm{~Hz}, 1 \mathrm{H}, \mathrm{Ar}-H), 7.06(\mathrm{dd}, J=8.1 \mathrm{~Hz}, J=$ 1.5, $1 \mathrm{H}, \operatorname{Ar}-\mathrm{H}), 3.74-3.02\left(\mathrm{~m}, 12 \mathrm{H}, \mathrm{N}-\mathrm{CH}_{2}\right), 2.21(\mathrm{~s}, 3 \mathrm{H}$, $\left.\mathrm{Ar}-\mathrm{CH}_{3}\right), 2.07\left(\mathrm{~m}, 4 \mathrm{H}, \mathrm{CH}_{2}\right), 1.66(\mathrm{~m}, 2 \mathrm{H}, \mathrm{CH}), 1.36(\mathrm{~m}, 16 \mathrm{H}$, $\left.\mathrm{CH}_{2}\right), 0.92\left(\mathrm{t}, 12 \mathrm{H}, \mathrm{CH}_{3}\right) .{ }^{13} \mathrm{C} \mathrm{NMR}\left(50 \mathrm{MHz}, \mathrm{DMSO}-d_{6}\right): \delta$ $(\mathrm{ppm})=153.7 / 153.2(C=\mathrm{O}), 136.3 / 136.2 / 129.9 / 129.7 / 108.3 /$ 103.2 (Ar), 51.7/51.5/50.3/50.2/47.7/46.9 (N-CH 2$), 37.4(C \mathrm{H})$, $31.5 / 31.3 / 27.9 / 27.7 / 24.2 / 24.1 / 22.3\left(\mathrm{CH}_{2}\right), 17.2\left(\mathrm{Ar}-\mathrm{CH}_{3}\right), 14 /$ $13.8 / 11.5 / 11.4\left(\mathrm{CH}_{3}\right)$.

Chain stopper S3. NaH (1.5 g) was placed in a three necked round bottomed flask and washed with pentane $(5 \mathrm{~mL})$ under a nitrogen atmosphere. A solution of $N$-(2-ethylhexyl)- $N{ }^{\prime}-(4-$ methylphenyl)urea [22] (1 g, $3.8 \mathrm{mmol})$ in dry THF (25 mL) was added and the mixture stirred for $1 \mathrm{~h}$. 1,3-Dibromopropane ( $3.9 \mathrm{~mL}, 38 \mathrm{mmol})$ in dry THF $(50 \mathrm{~mL})$ was then added, and the solution heated under reflux for $24 \mathrm{~h}$. After cooling, ice was slowly added and the solvent evaporated. Chloroform $(50 \mathrm{~mL})$ was added and the organic phase washed successively with brine $(70 \mathrm{~mL})$ and water $(2 \times 70 \mathrm{~mL})$, dried over magnesium sulfate and concentrated. Silica gel column chromatography (ethyl acetate/dichloromethane and then ethyl acetate) followed by recrystallization from pentane afforded $0.66 \mathrm{~g}$ of a white solid (57\%). ${ }^{1} \mathrm{H}$ NMR $\left(200 \mathrm{MHz}, \mathrm{DMSO}-d_{6}\right): \delta(\mathrm{ppm})=7.42 /$ $7.17(2 \mathrm{~d}, 4 \mathrm{H}, \mathrm{Ar}-\mathrm{H}), 3.21\left(\mathrm{~m}, 6 \mathrm{H}, \mathrm{N}-\mathrm{CH}_{2}\right), 2.15(\mathrm{~s}, 3 \mathrm{H}$, $\left.\mathrm{Ar}-\mathrm{CH}_{3}\right), 1.78\left(\mathrm{~m}, 3 \mathrm{H}, \mathrm{CH}_{2}(\right.$ cycle $\left.)+\mathrm{CH}\right), 1.32\left(\mathrm{~m}, 8 \mathrm{H}, \mathrm{CH}_{2}\right)$, $0.93\left(\mathrm{t}, 6 \mathrm{H}, \mathrm{CH}_{3}\right)$.

Chain stopper S4. 2-Ethylhexylamine $(8.8 \mathrm{~mL}, 52 \mathrm{mmol})$ in dichloromethane $(50 \mathrm{~mL})$ was added slowly under a nitrogen atmosphere to a stirred solution of 2,4-toluene diisothiocyanate (5.06 g, $24.5 \mathrm{mmol})$ in dichloromethane $(200 \mathrm{~mL}$, distilled over calcium hydride). After $24 \mathrm{~h}$, the solvent was evaporated. Recrystallization from ethanol/water afforded $7.74 \mathrm{~g}$ of a white solid (68\%). ${ }^{1} \mathrm{H}$ NMR (250 MHz, DMSO- $\left.d_{6}, \delta(\mathrm{ppm})\right)$ : 9.47/ $9.04(2 \mathrm{~s}, 2 \mathrm{H}, \mathrm{Ar}-\mathrm{NH}), 7.52 / 7.37\left(2 \mathrm{~s}, 2 \mathrm{H}, \mathrm{CH}_{2}-\mathrm{NH}\right), 7.32$ (s, $1 \mathrm{H}$, Ar-H), 7.21-7.11 (m, 2H, Ar- $H$ ), $3.40\left(\mathrm{~m}, 4 \mathrm{H}, \mathrm{N}-\mathrm{CH}_{2}\right), 2.14$ (s, $\left.3 \mathrm{H}, \mathrm{Ar}-\mathrm{CH}_{3}\right), 1.59(\mathrm{~m}, 2 \mathrm{H}, \mathrm{CH}), 1.25\left(\mathrm{~m}, 16 \mathrm{H}, \mathrm{CH}_{2}\right), 0.84(\mathrm{~m}$, $\left.12 \mathrm{H}, \mathrm{CH}_{3}\right) .{ }^{13} \mathrm{C}$ NMR $\left(62.5 \mathrm{MHz}, \mathrm{DMSO}-d_{6}, \delta(\mathrm{ppm})\right): 181.2 /$ $180.4(C=\mathrm{S}), 137.0 / 130.6 / 130.0 / 122.6 / 121.1(A r), 47.4 / 47.1$ $\left(\mathrm{N}-\mathrm{CH}_{2}\right), 38.4 / 38.3(\mathrm{CH}), 30.5 / 28.4 / 23.8 / 22.6\left(\mathrm{CH}_{2}\right), 17.1(\mathrm{Ar}-$ $\left.\mathrm{CH}_{3}\right), 14.0 / 10.7\left(\mathrm{CH}_{3}\right)$. MS $(\mathrm{ESI})=[\mathrm{M}-\mathrm{H}] 463.4$

\section{Viscometry}

Solutions were prepared by stirring at room temperature for at least 1 day prior to use. Capillary viscosity was measured at $25 \pm 0.1{ }^{\circ} \mathrm{C}$ with an automatic Anton-Paar AMVn viscometer (capillary internal diameter $1.8 \mathrm{~mm}$; ball diameter $1.5 \mathrm{~mm}$ ). The measurements were performed with an angle of $20^{\circ}$ and repeated six times.

\section{FTIR spectroscopy}

Infrared spectra were recorded on a Nicolet Avatar 320 spectrometer in $\mathrm{KBr}$ cells of 0.3 to $2.5 \mathrm{~cm}$ path length.

\section{SANS}

Measurements were made at the LLB (Saclay, France) on the Paxy instrument, at three distance-wavelength combinations to cover the $310^{-3}$ to $0.3 \AA^{-1}$ q-range, where the scattering vector $\mathrm{q}$ is defined as usual, assuming elastic scattering, as $q=(4 \pi / \lambda) \sin (\theta / 2)$, where $\theta$ is the angle between incident and scattered beam. The sample diaphragm was $7.6 \mathrm{~mm}$. Collimation was achieved with a diaphragm of $22 \mathrm{~mm}$ for a sample detector distance of $1.5 \mathrm{~m}$, or $16 \mathrm{~mm}$ for a sample - detector 
distance of 3.2 and $6.7 \mathrm{~m}$. Data were corrected for the empty cell signal and the solute and solvent incoherent background. A light water standard was used to normalize the scattered intensities into $\mathrm{cm}^{-1}$ units.

\section{Acknowledgements}

O. Bénaud is acknowledged for his contribution to this project. We thank François Boué (LLB, Saclay) for assistance with SANS experiments.

\section{References}

1. Ciferri, A., Ed. Supramolecular Polymers; Marcel Dekker: New York, 2005.

2. Brunsveld, L.; Folmer, B. J. B.; Meijer, E. W.; Sijbesma, R. P. Chem. Rev. 2001, 101, 4071-4097. doi:10.1021/cr990125q

3. Bouteiller, L. Adv. Polym. Sci. 2007, 207, 79-112. doi:10.1007/12_2006_110

4. van der Gucht, J.; Besseling, N. A. M.; Knoben, W.; Bouteiller, L.; Cohen Stuart, M. A. Phys. Rev. B 2003, 67, 051106. doi:10.1103/PhysRevE.67.051106

5. Ducouret, G.; Chassenieux, C.; Martins, S.; Lequeux, F.; Bouteiller, L. J. Colloid Interface Sci. 2007, 310, 624-629. doi:10.1016/j.jcis.2007.01.059

6. Shikata, T.; Nishida, T.; Isare, B.; Linares, M.; Lazzaroni, R.; Bouteiller, L. J. Phys. Chem. B 2008, 112, 8459-8465. doi:10.1021/jp800495v

7. van Gorp, J. J.; Vekemans, J. A. J. M.; Meijer, E. W. J. Am. Chem. Soc. 2002, 124, 14759-14769. doi:10.1021/ja020984n

8. Ogata, D.; Shikata, T.; Hanabusa, K. J. Phys. Chem. B 2004, 108, 15503-15510. doi:10.1021/jp0486604

9. Sakamoto, A.; Ogata, D.; Shikata, T.; Hanabusa, K. Macromolecules 2005, 38, 8983-8986. doi:10.1021/ma051489p

10. Terech, P.; Weiss, R. G. Chem. Rev. 1997, 97, 3133-3159. doi: $10.1021 /$ cr9700282

11. van Esch, J. H.; Feringa, B. L. Angew. Chem., Int. Ed. 2000, 39, 2263-2266. doi:10.1002/1521-3773(20000703)39:13<2263::AID-ANIE2263>3.0.CO ;2-V

12. Sangeetha, N. M.; Maitra, U. Chem. Soc. Rev. 2005, 34, 821-836. doi:10.1039/b417081b

13. George, M.; Weiss, R. G. Acc. Chem. Res. 2006, 39, 489-497. doi:10.1021/ar0500923

14. Folmer, B. J. B.; Cavini, E.; Sijbesma, R. P.; Meijer, E. W. Chem. Commun. 1998, 1846-1848.

15. Ercolani, G. Chem. Commun. 2001, 1416-1417. doi:10.1039/b101678b

16. Pinault, T.; Cannizzo, C.; Andrioletti, B.; Ducouret, G.; Lequeux, F.; Bouteiller, L. Langmuir 2009, 25, 8404-8407. doi:10.1021/la804138u

17. Lortie, F.; Boileau, S.; Bouteiller, L.; Chassenieux, C.; Lauprêtre, F. Macromolecules 2005, 38, 5283-5287. doi:10.1021/ma050168a

18. Knoben, W.; Besseling, N. A. M.; Cohen Stuart, M. A. Macromolecules 2006, 39, 2643-2653. doi:10.1021/ma0518914

19. Knoben, W.; Besseling, N. A. M.; Bouteiller, L.; Cohen Stuart, M. A. Phys. Chem. Chem. Phys. 2005, 7, 2390-2398. doi:10.1039/b503463a

20. Hirschberg, J. H. K.; Ramzi, A.; Sijbesma, R. P.; Meijer, E. W. Macromolecules 2003, 36, 1429-1432. doi:10.1021/ma025723c
21. Dudek, S. P.; Pouderoijen, M.; Abbel, R.; Schenning, A. P. H. J.; Meijer, E. W. J. Am. Chem. Soc. 2005, 127, 11763-11768. doi:10.1021/ja052054k

22. Simic, V.; Bouteiller, L.; Jalabert, M. J. Am. Chem. Soc. 2003, 125 13148-13154. doi:10.1021/ja037589x

23. Bouteiller, L.; Colombani, O.; Lortie, F.; Terech, P. J. Am. Chem. Soc. 2005, 127, 8893-8898. doi:10.1021/ja0511016

24. Bellot, M.; Bouteiller, L. Langmuir 2008, 24, 14176-14182. doi:10.1021/la802367r

25. Vonau, F.; Suhr, D.; Aubel, D.; Bouteiller, L.; Reiter, G.; Simon, L. Phys. Rev. Lett. 2005, 94, 066103. doi:10.1103/PhysRevLett.94.066103

26. Vonau, F.; Aubel, D.; Bouteiller, L.; Reiter, G.; Simon, L. Phys. Rev. Lett. 2007, 99, 086103. doi:10.1103/PhysRevLett.99.086103

27. Vonau, F.; Linares, M.; Isare, B.; Aubel, D.; Habar, M.; Bouteiller, L.; Reiter, G.; Geskin, V.; Zerbetto, F.; Lazzaroni, R.; Simon, L. J. Phys. Chem. C 2009, 113, 4955-4959. doi:10.1021/jp809552j

28. Boileau, S.; Bouteiller, L.; Lauprêtre, F.; Lortie, F. New J. Chem. 2000, 24, 845-848. doi:10.1039/b006742n

29. Pinault, T.; Isare, B.; Bouteiller, L. ChemPhysChem 2006, 7, 816-819. doi:10.1002/cphc.200500636

30. Isare, B.; Linares, M.; Lazzaroni, R.; Bouteiller, L. J. Phys. Chem. B 2009, 113, 3360-3364. doi:10.1021/jp810236z

31. Isare, B.; Linares, M.; Zargarian, L.; Fermandjian, S.; Miura, M.; Motohashi, S.; Vanthuyne, N.; Lazzaroni, R.; Bouteiller, L. Chem.-Eur. J. 2010, 16, 173-177. doi:10.1002/chem.200902399

32. Lortie, F.; Boileau, S.; Bouteiller, L.; Chassenieux, C.; Demé, B.; Ducouret, G.; Jalabert, M.; Lauprêtre, F.; Terech, P. Langmuir 2002, 18, 7218-7222. doi:10.1021/la0255166

33. Katz, H. E.; Cram, D. J. J. Am. Chem. Soc. 1984, 106, 4977-4987. doi:10.1021/ja00329a058

34. Laurence, C.; Berthelot, M.; Le Questel, J.-Y.; El Ghomari, M. J. J. Chem. Soc., Perkin Trans. 2 1995, 2075-2079. doi:10.1039/p29950002075

35. Masunov, A.; Dannenberg, J. J. J. Phys. Chem. B 2000, 104, 806-810. doi:10.1021/jp993078e

36. SANS experiments have been performed for EHUT solutions in $d_{8}$-toluene, in the presence of chain stopper $\mathbf{S} 1$ or $\mathbf{S 2}$ ([EHUT] $=11$ $\mathrm{mM}$; [stopper]/[EHUT] $=0.2)$. In the q-range investigated $\left(3.1610^{-3}-\right.$ $3.1410^{-1} \AA^{-1}$ ), the scattering curves are virtually the same as without chain-stopper (data not shown). This indicates that the local structure is not significantly affected.

37. Nowick, J. S.; Powell, N. A.; Martinez, E. J.; Smith, E. M.; Noronha, G. J. Org. Chem. 1992, 57, 3763-3765. doi:10.1021/jo00040a007 


\section{License and Terms}

This is an Open Access article under the terms of the Creative Commons Attribution License

(http://creativecommons.org/licenses/by/2.0), which permits unrestricted use, distribution, and reproduction in any medium, provided the original work is properly cited.

The license is subject to the Beilstein Journal of Organic Chemistry terms and conditions:

(http://www.beilstein-journals.org/bjoc)

The definitive version of this article is the electronic one which can be found at:

doi:10.3762/bjoc.6.102 